\title{
Biochar Source and Application Rate Effects on Soil Water Retention Determined Using Wetting Curves
}

\author{
Katy E. Brantley, Kristofor R. Brye, Mary C. Savin, David E. Longer \\ Department of Crop, Soil, and Environmental Sciences, University of Arkansas, Fayetteville, USA \\ Email: kbrye@uark.edu
}

Received 19 December 2014; revised 30 December 2014; accepted 7 January 2015

Copyright (C 2015 by authors and Scientific Research Publishing Inc.

This work is licensed under the Creative Commons Attribution International License (CC BY). http://creativecommons.org/licenses/by/4.0/

(c) $\underset{\mathrm{EY}}{0}$ Open Access

\begin{abstract}
Biochar is a stable carbon substance produced by the pyrolysis of biomass and used as a soil amendment. Biochar application to soil has resulted in agronomic benefits, including improved water-holding capacity. However, limited studies exist quantifying different biochars' roles in soil water retention, especially when the soil is drier than field capacity. The objective of this study was to investigate the effects of poultry litter and woodchip biochars, applied at various rates (i.e., 0,5 , and $10 \mathrm{Mg} \cdot \mathrm{ha}^{-1}$ incorporated to a depth of $10 \mathrm{~cm}$ ) to a loam soil, on the relationship between soil water potential and water content across a wide range of moisture conditions. Based on analysis of variance, the relationship between water potential and water content differed $(P<0.05)$ between biochar sources based on differing $(P<0.02)$ power-function coefficients, with poultry litter biochar having greater water retention capacity across a wide range of water potentials, but was unaffected by application rate. Based on regression analyses, application rate affected the relationship between water potential and water content for poultry litter biochar. Results indicate that biochar may not generally improve water retention at all water contents with one-time application rates. Additional experiments will be necessary to understand the impact on water retention of biochars produced from different feedstocks under varying pyrolysis conditions.
\end{abstract}

\section{Keywords}

Biochar, Poultry Litter, Water Retention

\section{Introduction}

Biochar is a charcoal product produced in high-heat and low-oxygen conditions that can be used as a soil

How to cite this paper: Brantley, K.E., Brye, K.R., Savin, M.C. and Longer, D.E. (2015) Biochar Source and Application Rate Effects on Soil Water Retention Determined Using Wetting Curves. Open Journal of Soil Science, 5, 1-10.

http://dx.doi.org/10.4236/ojss.2015.51001 
amendment with the potential for enhancing soil properties and plant growth. Biochar can have large surface area and high porosity, tending to increase with increasing pyrolysis temperature until around $850^{\circ} \mathrm{C}[1]$ [2]. Brown et al. [1] reported pitch pine (Pinus rigida) biochar surface area peaking near $400 \mathrm{~m}^{2} \cdot \mathrm{g}^{-1}$, while Lua et al. [2] reported a surface area over $700 \mathrm{~m}^{2} \cdot \mathrm{g}^{-1}$ and pore volume exceeding $0.45 \mathrm{~cm}^{3} \cdot \mathrm{g}^{-1}$ with pistachio (Pistacia ve$r a$ )-nut biochar. Like ashes, many biochar products have alkaline $\mathrm{pH}$ [3] [4], which can decrease soil acidity, creating a more favorable habitat for many plants and microbes. Soils with biochar addition have been shown to increase nutrient contents and improve nutrient-holding capacity, potentially through direct nutrient addition [3] [5]-[7], as well as increase soil water-holding capacity [8] [9].

Research is ongoing to confirm these previous reports since the assumption that benefits will occur may not hold true with all biochar products (i.e., feedstocks and processing characteristics), field and soil conditions, management practices, and crops grown. In a greenhouse experiment, Rajkovich et al. [10] investigated the effects of over 30 different biochars produced from corn (Zea mays) stover, nut shells, woodchips, manures, and sawdust bedding at four different pyrolysis temperatures on corn growth and reported differences between feedstock source, pyrolysis temperature, application rate on corn biomass, plant growth, nitrogen concentration, and total nitrogen uptake. Novak et al. [11] reported that greater biochar production temperatures could produce more alkaline $\mathrm{pH}$, greater ash contents, and greater surface areas in the biochar and could result in increased soil $\mathrm{pH}$.

Biochar has also been observed to increase soil-water retention [8] [12]-[14]. Laird et al. [8] reported greater water retention at gravity-drained equilibrium and -100 and $-500 \mathrm{kPa}$ water potentials in a Hapludoll from Iowa with mixed hardwood biochar. Utilizing an incubation and leaching experiment to determine the percentage of water retained in pots, Novak et al. [11] reported varied results depending on the biochar feedstock used; switchgrass (Panicum virgatum) biochar maximized soil-water retention when applied at a $40 \mathrm{Mg} \cdot \mathrm{ha}^{-1}$ application rate incorporated to a depth of $15 \mathrm{~cm}$ to loamy sand compared to poultry litter, pecan (Carya illinoinensis) shell, and peanut (Arachis hypogaea) hull biochars. A similar experimental design was used to test soil-water retention at -5 and $-60 \mathrm{kPa}$ with switchgrass biochar produced at $500^{\circ} \mathrm{C}$ resulting in the greatest soil-water retention [9]. Birch (Betula spp.) biochar added to a silt loam in Finland increased soil water-holding capacity by $11 \%$ compared to the unamended control [13]. Based on moisture release curve data from a laboratory experiment with loamy sand, only the addition of peanut hull biochar applied at $88 \mathrm{Mg} \cdot \mathrm{ha}^{-1}$ increased soil water-holding capacity compared to lower biochar rates and various woodchip biochar types [12]. In a Brazilian sandy clay loam, sugarcane (Saccharum spp.) filtercake biochar addition led to greater water retention within the plant available water range, even though drier soils were also evaluated [15].

Many of the preexisting studies related to the effects of biochar on water-holding capacity involved the use of techniques that evaluate maximum water-holding capacity and plant-available water (i.e., field capacity at $\sim-0.03$ MPa to permanent wilting point at $\sim-1.5 \mathrm{MPa}$ ) in soil [8] [16]-[18]. The relationship between soil water potential and soil water content can be determined from data generated by drying saturated soil cores with the application of pressure using a pressure-plate apparatus [8] [16] [17] [19] [20]. Another method quantified the volume of water in samples centrifuged at speeds corresponding to matric potentials between saturation and the permanent wilting point [21]. Pot water-holding capacities were used by Novak et al. [9] [11] to represent gravimetric soil moisture contents in incubation leaching experiments, while Major et al. [22] used tensiometers in the field. Investigating a wider range of moisture conditions, Sun et al. [23] investigated water retention to matric potentials close to $-7 \mathrm{MPa}$, and sugarcane water retention effects were examined in Brazil using a Dewpoint Potentiameter [15]. Systematically, rewetting dry soil samples and measuring corresponding water-potential responses (i.e., determining the soil wetting curve) facilitates a thorough and orderly comparison among soil amendment effects of water retention characteristics.

Though most previous studies have concentrated on moist-soil conditions, it is not always possible to keep managed fields at field capacity. Dry-land agriculture in particular is prone to drought conditions and may become more common as changes in climate continue. Consequently, additional research is necessary to shed light on potential water-holding capacity improvements from biochar amendment over a wider range of soil moisture conditions. Therefore, the objective of this study was to investigate the effect of poultry litter and woodchip biochars, applied at various rates to a loam soil, on the relationship between a wide range of soil-water potentials and water contents using soil wetting curves. It was predicted that the type (i.e., feedstock source) of biochar added to soil at varying rates would differentially affect water-retention characteristics determined using soil wetting curves. Specifically, it was hypothesized that poultry litter biochar applied at the greatest rate would alter water-retention characteristics more than at lower rates or with the woodchip biochar due to the intrinsic dif- 
ferences in the biochar products.

\section{Materials and Methods}

\subsection{Soil Sample Collection and Initial Characterization}

Soil was collected from approximately the top $10 \mathrm{~cm}$ of a floodplain at the University of Arkansas Agricultural Research and Extension Center in Fayetteville, Arkansas $\left(36.09390^{\circ} \mathrm{N}, 94.16494^{\circ} \mathrm{W}\right)$ in an area that was classified as a Razort loam (fine-loamy, mixed, active, mesic Mollic Hapludalf) [24], which was where soil was collected for asimilar greenhouse experiment. The soil was homogenized, air-dried for 72 hours, ground, and sieved to pass a 2-mm mesh screen. Four sub-samples were dried for 24 hours at $105^{\circ} \mathrm{C}$ to quantify the initial moisture content of the air-dried soil. Soil particle-size analysis was conducted on oven-dry sub-samples of the soil sieved through a 2-mm mesh screen using an adaptation of the 12-hr hydrometer method [25]. Mehlich-3 extractable nutrients (i.e., phosphorus $(\mathrm{P})$, potassium $(\mathrm{K})$, calcium $(\mathrm{Ca})$, magnesium $(\mathrm{Mg})$, sulfur $(\mathrm{S})$, iron $(\mathrm{Fe})$, manganese $(\mathrm{Mn})$ and copper $(\mathrm{Cu})$ ) were determined by inductively coupled plasma (ICP) spectrometry (SPECTRO ARCOS, SPECTRO Analytical Instruments GmbH, Kleve, Germany) [26]. Electrical conductivity (EC) and pH were determined potentiometrically on a 1:2 soil mass-to-water volume paste, and organic matter concentration was determined by loss-on-ignition in a muffle furnace.

\subsection{Biochar Characteristics}

Granular pine (Pinus spp.) woodchip biochar (Waste To Energy Solutions Inc., Destin, FL), produced through pyrolysis at $500^{\circ} \mathrm{C}$, was obtained for use in this study. Pelletized poultry litter biochar (Whitfield Biochar, Burlington, WA), produced through pyrolysis at $500^{\circ} \mathrm{C}$ to $520^{\circ} \mathrm{C}$, was also obtained for use in this study. These two biochar types were used as soil amendments to represent a cultivated-soil scenario.

Total recoverable minerals (i.e., $\mathrm{P}, \mathrm{K}, \mathrm{Ca}, \mathrm{Mg}$, S, sodium (Na), Fe, Mn, zinc ( $\mathrm{Zn}$ ), $\mathrm{Cu}$ and boron (B)) were determined from acid digests [27] by ICP spectrometry. Both biochars were dried for at least 48 hours at $70^{\circ} \mathrm{C}$ then ground to pass a 40-mesh screen. Biochar $\mathrm{pH}$ and $\mathrm{EC}$ were determined potentiometrically on a 1:2 sample mass-to-water volume paste. Sub-samples of each biochar were subsequently dried for 24 hours at $105^{\circ} \mathrm{C}$ to obtain moisture contents of both biochar materials. The water droplet penetration time (WDPT) test was measured using a modification of the procedure described by Herath et al. [28]. Three drops of water from a Pasteur pipet were added to $2 \mathrm{~g}$ of each biochar and the time of penetration was recorded [29] [30].

\subsection{Wetting Curve Determinations}

Following the procedures of Brye [31], the relationship between water potential and water content was determined for each of five replicate treatment combinations by re-wetting air-dry soil from randomly selected biochar source-rate treatment combinations. Brye [31] used this technique to determine the effect of years of cultivation and land use on soil water-retention characteristics. Eight sub-samples of air-dried sieved soil from each treatment combination were prepared by mixing $5 \pm 0.01 \mathrm{~g}$ of soil with $0,28 \mathrm{mg}$, or $57 \mathrm{mg}$ of biochar (i.e., equivalent to 0,5 , and $10 \mathrm{Mg} \cdot \mathrm{ha}^{-1}$ rates incorporated to a depth of $10 \mathrm{~cm}$ at the field scale). Soil and biochar samples were placed into small cups to which $1,2,4,6,10,12,15$, or 20 drops of distilled water were added to each sample cup, respectively, using a Pasteur pipet and mixed thoroughly. The moist soil and biochar mixtures were transferred to small plastic measurement vessels, $3.8 \mathrm{~cm}$ in diameter and $1 \mathrm{~cm}$ tall, and lightly tamped to fit into the bottom $0.5 \mathrm{~cm}$ of the cup, resulting in a dry bulk density of each sample $<1 \mathrm{~g} \cdot \mathrm{cm}^{-3}$. Sample vessels were covered and allowed to equilibrate overnight at room temperature. The following day, a WP4 Dewpoint Potentiameter (Decagon Devices, Inc., Pullman, WA) was used to measure the resulting water potential for each sample. The potentiameter was calibrated using 0.5 molal $\mathrm{KCl}$ standard solution. After the water potential was measured for each sample, the gravimetric water content was determined by weighing, oven-drying at $105^{\circ} \mathrm{C}$ for at least 12 hours, and reweighing.

\subsection{Data Analyses}

Initial biochar properties were compared between biochar sources by analysis of variance (ANOVA) using SAS (version 9.2, SAS Institute, Inc., Cary, NC). When appropriate, means were separated by least significant difference at $P=0.05$. 
The relationship between soil water potential $(\psi)$ and gravimetric water content $(\theta g)$ was determined using nonlinear regression as described in Brye [31] using the power function:

$$
\Psi=a(\theta g)^{-b}
$$

The power function was fit to the soil wetting curve data for each replicate treatment combination, with $\psi$ representing soil water potential (in $\mathrm{MPa}$ ), $\theta g$ representing the gravimetric water content of a given sample (in \%), and $\mathrm{a}$ and $\mathrm{b}$ were empirically derived coefficients. Based on a completely random design, a two-factor ANOVA was conducted using SAS to determine the effects of biochar source, rate, and their interaction on modeled water-retention characteristics (i.e., $a$ and $b$ coefficients). When appropriate, means were separated by least significant difference at $P=0.05$. A multiple regression analysis was also conducted on the modeled water-retention characteristics using Minitab (version 13.31, Minitab, Inc., State College, PA) to further investigate the effect of biochar rate.

\section{Results and Discussion}

\subsection{Initial Soil and Biochar Properties}

Initial soil and biochar properties were similar to expectations. Particle-size analyses confirmed the texture of the soil to be loam and the soil $\mathrm{pH}$ was determined to be 6.7 (Table 1 ). The poultry litter and woodchip biochars possessed alkaline $\mathrm{pH}$ of 8.0 and 8.9 , respectively (Table 2). The majority of the nutrient concentrations and EC differed $(P<0.05)$ between the two biochars. Except for iron, the poultry litter biochar possessed greater $(P<$ 0.05) concentrations of all other total recoverable elements measured (i.e., $\mathrm{P}, \mathrm{K}, \mathrm{Ca}, \mathrm{Mg}, \mathrm{S}, \mathrm{Na}, \mathrm{Mn}, \mathrm{Zn}, \mathrm{Cu}$; Table 2). The water repellency differed between the two biochars $(P<0.05)$, with greater water repellency in the poultry litter ( $>60$ seconds for water to penetrate into biochar) compared to the woodchip biochar ( 2.5 seconds).

Biochars can have large surface areas $\left(200\right.$ to $\left.>500 \mathrm{~m}^{2} \cdot \mathrm{g}^{-1}\right)$ and are highly porous when produced at intermediate temperatures around $450^{\circ} \mathrm{C}$ to $750^{\circ} \mathrm{C}$ [1] [2] [32], a range which includes the temperatures that produced the biochars used in this study. These physical biochar attributes have affected water relationships in soil by increasing soil porosity and changing the pore-size distribution [17] [33]. In this study, the short duration of the experiment and the pre-treatment of the biochars, including air-drying and sieving, eliminated some possible mechanisms of biochar effect on soil water-retention (e.g., improved soil structure, aggregate stability, and the increase of macropores). Grinding the biochar created a more uniform comparison between biochars so that their intrinsic property differences rather than their structural differences (i.e., pellet vs. granular) were likely responsible for subsequent measured differences in the relationship between water potential and water content.

\subsection{Soil Wetting Curve Differences}

The power function (Equation (1)) fit the soil wetting curve data well, with $\mathrm{R}^{2}$ values of 0.94 and 0.95 (Figure 1). Water contents measured in this study included those in the plant available water range as well as those drier than permanent wilting point (i.e., water potentials ranging from $\sim-0.2$ to $\sim-80 \mathrm{MPa}$; Figure 1). The $a$ coefficient of the wetting-curve model, an experimentally derived coefficient, differed $(P=0.018)$ between biochar sources (Table 3). Averaged across biochar rate, the $a$ coefficient from the wetting-curve model averaged 277.1 for the poultry litter and 392.8 for the woodchip biochars (Figure 1). However, despite the differences in the rate of biochar addition, biochar rate did not affect $(P>0.05)$ the $a$ coefficient of the soil wetting-curve model (Table 3). These results suggest that soil response was similar across biochar rates, but that differences existed based on the biochar source, potentially different pore structures, requiring significant adjustments in the model's $a$ coefficient [31].

The $b$ coefficient of Equation (1) characterizes the rate of water potential decrease as the water content decreased [31]. Similar to the $a$ coefficient, the $b$ coefficient also differed between biochar sources $(P=0.001)$, but was unaffected $(P>0.05)$ by biochar rate (Table 3$)$. Combined across biochar rates, the $b$ coefficient from the wetting-curve model averaged -2.36 for the poultry litter and -2.62 for the woodchip biochars (Figure 1 ). The more negative $b$ coefficient for the woodchip biochar treatments indicated that the water content decrease was greater for the woodchip than for the poultry litter biochar for the same decrease in water potential. Conse- 
Table 1. Initial mean ( \pm standard error (SE)) particle-size distribution, $\mathrm{pH}$, electrical conductivity (EC), organic matter, and Mehlich-3 extractable nutrients for the Razort soil $(n=4)$.

\begin{tabular}{lc}
\hline \multicolumn{1}{c}{ Soil property } & Mean $( \pm$ SE) \\
\hline Particle-size distribution $\left(\mathrm{g} \cdot \mathrm{g}^{-1}\right)$ & $0.40(0.01)$ \\
$\quad$ Sand & $0.47(0.01)$ \\
Silt & $0.13(<0.01)$ \\
Clay & $6.7(0.1)$ \\
$\mathrm{pH}$ & $0.3(0.2)$ \\
$\mathrm{EC}\left(\mathrm{dS} \cdot \mathrm{m}^{-1}\right)$ & $3.5(0.1)$ \\
Organic matter $(\%)$ & $5.2(0.5)$ \\
Phosphorus $\left(\mu \mathrm{g} \cdot \mathrm{g}^{-1}\right)$ & $84.9(15)$ \\
Potassium $\left(\mu \mathrm{g} \cdot \mathrm{g}^{-1}\right)$ & $1191(26)$ \\
Calcium $\left(\mu \mathrm{g} \cdot \mathrm{g}^{-1}\right)$ & $47.4(0.2)$ \\
Magnesium $\left(\mu \mathrm{g} \cdot \mathrm{g}^{-1}\right)$ & $14.0(5.9)$ \\
Sulfur $\left(\mu \mathrm{g} \cdot \mathrm{g}^{-1}\right)$ & $48.9(1.8)$ \\
Iron $\left(\mu \mathrm{g} \cdot \mathrm{g}^{-1}\right)$ & $93.1(3.7)$ \\
Manganese $\left(\mu \mathrm{g} \cdot \mathrm{g}^{-1}\right)$ & $1.1(0.02)$ \\
Copper $\left(\mu \mathrm{g} \cdot \mathrm{g}^{-1}\right)$ &
\end{tabular}

Table 2. Initial mean ( \pm standard error (SE)) pH, electrical conductivity (EC), total carbon (C), total nitrogen $(\mathrm{N}), \mathrm{C}: \mathrm{N}$ ratio, and total recoverable minerals for poultry litter and woodchip biochar sources $(n=2)$.

\begin{tabular}{ccc}
\hline Biochar property & \multicolumn{2}{c}{ Biochar source } \\
\cline { 2 - 3 } $\mathrm{pH}$ & $8.0(0.04)^{*} a$ & Woodchip \\
\hline $\mathrm{EC}\left(\mathrm{dS} \cdot \mathrm{m}^{-1}\right)$ & $42.0(0.01) a$ & $8.9(0.03) b$ \\
Total Carbon $\left(\mathrm{g} \cdot \mathrm{kg}^{-1}\right)$ & $337.2(2.5) a$ & $4.6(0.02) b$ \\
Total Nitrogen $\left(\mathrm{g} \cdot \mathrm{kg}^{-1}\right)$ & $34.9(0.06) a$ & $244.5(21) b$ \\
C:N ratio & $9.7: 1(0.05) a$ & $0.7(0.2) b$ \\
Phosphorus $\left(\mathrm{g} \cdot \mathrm{kg}^{-1}\right)$ & $25.7(0.2) a$ & $366: 1(64) b$ \\
Potassium $\left(\mathrm{g} \cdot \mathrm{kg}^{-1}\right)$ & $52.4(0.2) a$ & $0.8(0.02) b$ \\
Calcium $\left(\mathrm{g} \cdot \mathrm{kg}^{-1}\right)$ & $45.4(5.8) a$ & $2.1(0.1) b$ \\
Magnesium $\left(\mathrm{g} \cdot \mathrm{kg}^{-1}\right)$ & $12.6(0.9) a$ & $10.1(0.5) b$ \\
Sulfur $\left(\mathrm{g} \cdot \mathrm{kg}^{-1}\right)$ & $13.6(0.3) a$ & $2.7(0.2) b$ \\
Sodium $\left(\mathrm{g} \cdot \mathrm{kg}^{-1}\right)$ & $15.3(0.6) a$ & $0.1(<0.01) b$ \\
Iron $\left(\mathrm{g} \cdot \mathrm{kg}^{-1}\right)$ & $1.4(0.1) a$ & $0.3(0.01) b$ \\
Manganese $\left(\mathrm{mg} \cdot \mathrm{kg}^{-1}\right)$ & $715.0(18) a$ & $0.9(0.1) a$ \\
Zinc $\left(\mathrm{mg} \cdot \mathrm{kg}^{-1}\right)$ & $829.5(26) a$ & $420.5(30) b$ \\
Copper $\left(\mathrm{mg} \cdot \mathrm{kg}^{-1}\right)$ & $583.0(40) a$ & 0.01 \\
Boron $\left(\mathrm{mg} \cdot \mathrm{kg}^{-1}\right)$ & $78.0(4.0) a$ & $6.5(0.04) b$ \\
\end{tabular}

${ }^{*}$ Means in the same row followed by different letters are different $(P<0.05) .{ }^{* *} Z$ inc in the woodchip biochar was below the detection limit of the method. Therefore, the detection limit of 0.01 was used for statistical analysis.

Table 3. Analysis of variance summary of the effects of biochar $(\mathrm{BC})$ source, rate, and their interaction on water-retention characteristics from soil wetting curve data fit to the model $\Psi=a\left(\theta_{g}\right)^{-b}$.

\begin{tabular}{cccc}
\hline Source of variation & Degrees of freedom & $\boldsymbol{a}$ coefficient & $\boldsymbol{b}$ coefficient \\
\cline { 3 - 4 } & 20 & 0.018 & 0.001 \\
Biochar source & 20 & 0.293 & 0.085 \\
Biochar rate & 20 & 0.365 & 0.291 \\
\hline
\end{tabular}




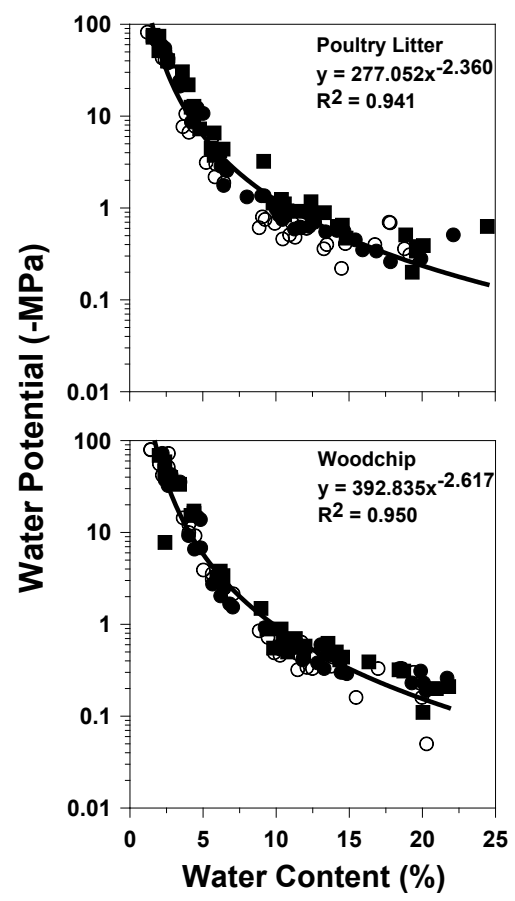

Figure 1. Relationship between water potential and gravimetric water content for poultry litter and woodchip biochars averaged over rate. The resulting fitted power function and associated coefficient of determination $\left(\mathrm{R}^{2}\right)$ are reported for each biochar source. The open circles are data points with $0 \mathrm{Mg} \cdot \mathrm{ha}^{-1}$, the filled circles with $5 \mathrm{Mg} \cdot \mathrm{ha}^{-1}$, and the filled squares with $10 \mathrm{Mg} \cdot \mathrm{ha}^{-1}$ biochar application.

quently, more water was retained at a given water potential with the poultry litter biochar than with the woodchip biochar.

Though ANOVA did not demonstrate a biochar rate effect, regression analyses were conducted to investigate a potential relationship between biochar rate and water retention assuming that biochar rate represented a continuous variable. The $a$ coefficient for the poultry litter biochar varied significantly $(P=0.037)$ as biochar rate increased, while the $a$ coefficient for the woodchip biochar and neither $b$ coefficients were affected by biochar rate (Table 4). The $a$ coefficient for the poultry litter biochar increased from the 0 to the $5 \mathrm{Mg} \cdot \mathrm{ha}^{-1}$ rate, then decreased from the 5 to the $10 \mathrm{Mg} \cdot \mathrm{ha}^{-1}$ rate (Figure 2 and Table 4), suggesting a change in biochar effect at the 5 $\mathrm{Mg} \cdot \mathrm{ha}^{-1}$ application rate compared to the control that was no longer observed at the greatest rate.

Considering results for both the $a$ and $b$ coefficients, the poultry-litter-biochar-amended soil possessed different overall water-retention characteristics than the woodchip-biochar-amended soil. Since the soil was uniformly treated by air-drying, grinding, and sieving and the biochars were oven-dried and ground, these results suggest that there were factors intrinsic to the biochars that potentially led to water-retention differences between biochar sources. The poultry litter biochar, with a significantly smaller $\mathrm{C}: \mathrm{N}$ ratio, significantly greater nutrient contents, and almost ten-fold numerically greater EC (Table 2), possessed a strikingly different composition that could have affected water-retention characteristics differently than those of the woodchip biochar. Water could have reacted with the inorganic nutrients and compounds in the poultry litter biochar, creating a physical adhesion effect to retain the water in the soil [9].

The greater $\mathrm{C}: \mathrm{N}$ ratio of the woodchip biochar, which suggests a greater lignin and cellulose concentration than in the poultry litter biochar due to its origin as plant material, could lead to greater hydrophobicity and water repellency. However, the poultry litter biochar possessed greater water repellency than the woodchip biochar. Fresh biochar tends to be water repellent [34], and Briggs et al. [35] speculated that the water repellency of their pine biochar samples had to do with the aliphatic compounds that make up biochar as well as the mineral-rich composition clogging outer pores. Tars in biochars can also repel water, and they remain in charcoal produced at temperatures below $600^{\circ} \mathrm{C}$ [32] [36]-[38], such as with the biochars used in this study. The original poultry litter biochar was a hydrophobic pellet, while the woodchip was a coarse, less compacted granular-like form, which could have resulted in differences in the biochars based on the processing and production conditions. Based on 
Table 4. Summary of multiple regression results for $a$ and $b$ coefficients from poultry litter and woodchip biochar and the effect of biochar rate and rate ${ }^{2}$.

\begin{tabular}{|c|c|c|c|c|c|c|}
\hline \multirow[b]{2}{*}{ Variable } & \multirow[b]{2}{*}{ Biochar source } & \multicolumn{2}{|c|}{ Regression coefficients } & \multirow[b]{2}{*}{ Intercept } & \multirow[b]{2}{*}{ Overall model } & \multirow[b]{2}{*}{$\mathbf{R}^{2}$} \\
\hline & & Rate & Rate $^{2}$ & & & \\
\hline & & & & & $P$ & \\
\hline \multirow[t]{2}{*}{$a$ coefficient } & Poultry litter & $78.2^{*}$ & $-7.16^{*}$ & $244^{*}$ & 0.037 & 0.42 \\
\hline & Woodchip & 4.05 & -0.34 & $479^{*}$ & 0.998 & 0.00 \\
\hline \multirow[t]{2}{*}{$b$ coefficient } & Poultry litter & -0.075 & 0.0086 & $-2.40^{*}$ & 0.100 & 0.32 \\
\hline & Woodchip & 0.0057 & 0.00052 & $-2.70^{*}$ & 0.790 & 0.04 \\
\hline
\end{tabular}

*Asterisks indicate values significantly different from $0(P<0.05)$.

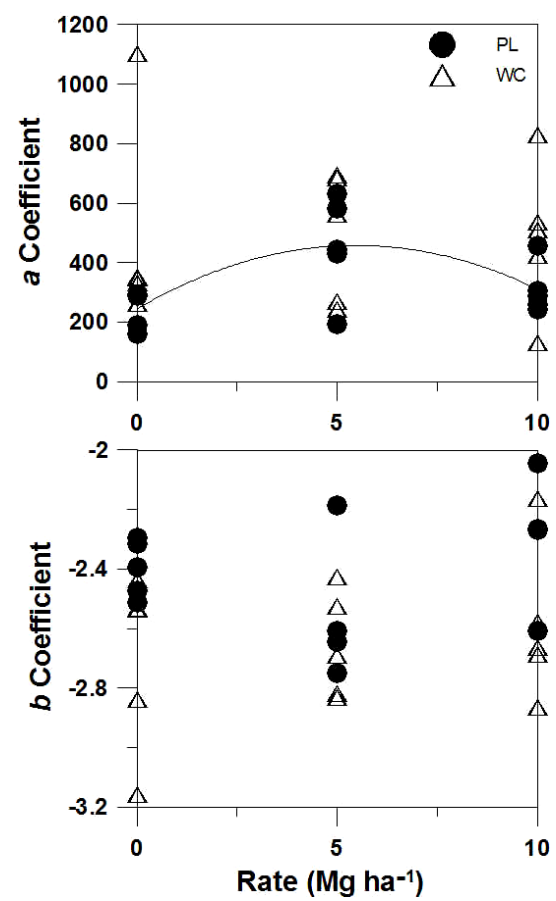

Figure 2. Effect of biochar rate on $a$ and $b$ coefficients from fitting the power function to soil wetting-curve data for poultry litter (PL) and woodchip (WC) biochars. The plotted line represents a significant regression model, where model parameters are summarized in Table 4.

visual observation, following grinding to facilitate comparison among intrinsic properties between biochars, the poultry litter biochar was composed of finer particles than the woodchip biochar. Grinding of the biochars for use in this study may have produced finer particles in the poultry litter biochar that filled soil pores more than the coarser woodchip biochar material to help retain water once soil applied.

Different biochar feedstocks, production temperatures, and environmental conditions (i.e., a greenhouse compared to a field setting) could also produce drastically different results than those observed in this study in terms of their effects on soil water-retention characteristics [1]. Thirty months after field application of $47 \mathrm{Mg} \cdot \mathrm{ha}^{-1}$ Acacia spp. Green waste biochar and incorporated to a depth of $10 \mathrm{~cm}$ in a silt loam, Hardie et al. [39] reported no significant effects on soil-water retention or soil moisture content near field capacity, but reported numerically greater water contents near saturation. Soil water-holding capacity was unaffected by $20 \mathrm{Mg} \cdot h a^{-1}$ of mixed wood species biochar incorporated to a depth of $5 \mathrm{~cm}$ in an Oxisol [22] or by $11 \mathrm{or} 22 \mathrm{Mg} \cdot \mathrm{ha}^{-1}$ of peanut ( $\mathrm{Ara}-$ chis hypogaea) hull, hardwood, or various pine biochars added to loamy sand [12]. In a laboratory experiment, plant-available water was shown to increase in sandy soil, remain unaffected in loamy soil, and decrease in clayey soil with the additions of hardwood and pine biochars from $0 \%$ to $15 \%, 30 \%$, and $45 \%$ (w/w) application rates [40]. After investigating 60 combinations of soils and biochars, Strebel et al. [41] reported 25 combinations 
resulting in significantly greater soil water-holding capacity. Furthermore, Abel et al. [42] reported biochar addition to a sandy soil decrease bulk density and increased available water-holding capacity and the water content at permanent wilting point, but biochar did not impact soil wettability six months after incorporation.

Though only a one-time biochar application was used in this study, there is potential that differing results could be observed if greater rates were used or if multiple biochar additions were made over time in a longer study. However, greater rates could prove uneconomical for field application [20]. The $\mathrm{Na}$ content in poultry litter biochar was roughly 50 times greater than that in the woodchip biochar; thus, repeated biochar additions, especially with the poultry litter biochar, could negatively impact soil water-holding capacity by increasing soil dispersion and off-setting the potential for improved soil structure. Future studies should also investigate the effects of other biochar products produced from different feedstocks and under various production and environmental conditions on soil water-retention characteristics.

\section{Conclusion}

Water-retention characteristics of a loam soil differed as a result of a single addition of poultry litter and woodchip biochar. Poultry litter biochar had different chemical characteristics and affected water-retention characteristics differently compared with woodchip biochar, although both biochars were produced from pyrolysis at approximately $500^{\circ} \mathrm{C}$. More water was retained at given water potential with the poultry litter biochar than with the woodchip biochar, but rate effects were minimal. The results of this study demonstrate that all biochars may not improve soil water retention over a wide range of soil moisture conditions at all application rates. Additional research with various biochar products applied at a range of application rates and with multiple applications would enhance knowledge of the effects of biochar amendment on soil water-retention characteristics.

\section{Acknowledgements}

Laboratory assistance provided by Melissa Fulenwider is gratefully acknowledged.

\section{References}

[1] Brown, R.A., Kercher, A.K., Nguyen, T.H., Nagle, D.C. and Ball, W.P. (2006) Production and Characterization of Synthetic Wood Chars for Use as Surrogates for Natural Sorbents. Organic Geochemistry, 37, 321-333. http://dx.doi.org/10.1016/j.orggeochem.2005.10.008

[2] Lua, A.C, Yang, T. and Guo, J. (2004) Effects of Pyrolysis Conditions on the Properties of Activated Carbons Prepared from Pistachio-Nut Shells. Journal of Analytical and Applied Pyrolysis, 72, 279-287. http://dx.doi.org/10.1016/j.jaap.2004.08.001

[3] Gaskin, J.W., Steiner, C., Harris, K., Das, K.C. and Bibens, B. (2008) Effect of Low-Temperature Pyrolysis Conditions on Biochar for Agricultural Use. Transactions of the American Society of Agricultural and Biological Engineers, 51, 2061-2069.

[4] Spokas, K.A., Cantrell, K.B., Novak, J.M., Archer, D.W., Ippolito, J.A., Collins, H.P., Boateng, A.A., Lima, I.M., Lamb, M.C., McAloon, A.J., Lentz, R.D. and Nichols, K.A. (2012) Biochar: A Synthesis of Its Agronomic Impact beyond Carbon Sequestration. Journal of Environmental Quality, 41, 973-989. http://dx.doi.org/10.2134/jeq2011.0069

[5] Glaser, B., Haumaier, L., Guggenberger, G. and Zech, W. (2001) The "Terra Preta" Phenomenon: A Model for Sustainable Agriculture in the Humid Tropics. Naturwissenschaften, 88, 37-41. http://dx.doi.org/10.1007/s001140000193

[6] Lehmann, J., da Silva Jr., J.P., Rondon, M., da Silva, C.M., Greenwood, J., Nehls, T., Steiner, C. and Glaser, B. (2002) Slash-and-char: A Feasible Alternative for Soil Fertility Management in the Central Amazon? 17th World Congress of Soil Science, Bangkok, 14-21 August 2002, 1-12.

[7] Lehmann, J., da Silva Jr., J.P., Steiner, C., Nehls, T., Zech, W. and Glaser, B. (2003) Nutrient Availability and Leaching in an Archaeological Anthrosol and a Ferralsol of the Central Amazon Basin: Fertilizer, Manure and Charcoal Amendments. Plant and Soil, 249, 343-357. http://dx.doi.org/10.1023/A:1022833116184

[8] Laird, D.A., Fleming, P., Davis, D.D., Horton, R., Wang, B. and Karlen, D.L. (2010) Impact of Biochar Amendments on the Quality of a Typical Midwestern Agricultural Soil. Geoderma, 158, 443-449. http://dx.doi.org/10.1016/j.geoderma.2010.05.013

[9] Novak, J.M., Busscher, W.J., Watts, D.W., Amonette, J.E., Ippolito, J.A., Lima, I.M., Gaskin, J., Das, K.C., Steiner, C., Ahmedna, M., Rehrah, D. and Schomberg, H. (2012) Biochars Impact on Soil-Moisture Storage in an Ultisol and Two Aridisols. Soil Science, 177, 310-320. http://dx.doi.org/10.1097/SS.0b013e31824e5593

[10] Rajkovich, S., Enders, A., Hanley, K., Hyland, C., Zimmerman, A.R. and Lehmann, J. (2012) Corn Growth and Nitro- 
gen Nutrition after Additions of Biochars with Varying Properties to a Temperate Soil. Biology and Fertility of Soils, 48, 271-284. http://dx.doi.org/10.1007/s00374-011-0624-7

[11] Novak, J.M., Lima, I., Xing, B., Gaskin, J.W., Steiner, C., Das, K.C., Ahmedna, M., Rehrah, D., Watts, D.W., Busscher, W.J. and Schomberg, H. (2009) Characterization of Designer Biochar Produced at Different Temperatures and Their Effects on a Loamy Sand. Annals of Environmental Science, 3, 195-206.

[12] Gaskin, J.W., Speir, A., Morris, L.M., Ogden, K., Harris, K., Lee, D. and Das, K.C. (2007) Potential for Pyrolysis Char to Affect Soil Moisture and Nutrient Retention Status of a Loamy Sand Soil. Proceedings of the 2007 Georgia Water Resources Conference, Athens, GA, 27-29 March 2007, 1-3.

[13] Karhu, K., Mattila, T., Bergström, I. and Regina, K. (2011) Biochar Addition to Agricultural Soil Increased $\mathrm{CH}_{4} \mathrm{Up}^{-}$ take and Water Holding Capacity-Results from a Short-Term Pilot Field Study. Agriculture, Ecosystems, and Environment, 140, 309-313. http://dx.doi.org/10.1016/j.agee.2010.12.005

[14] Major, J., Steiner, C., Downie, A. and Lehmann, J. (2009) Biochar Effects on Nutrient Leaching. In: Lehmann, J. and Joseph, S., Eds., Biochar for Environmental Management: Science and Technology, Earthscan Publishers Ltd., London, 271-287.

[15] Eykelbosh, A.J., Johnson, M.S., de Queiroz, E.S., Dalmagro, H.J. and Couto, E.G. (2014) Biochar from Sugarcane Filtercake Reduces Soil $\mathrm{CO}_{2}$ Emissions Relative to Raw Residue and Improves Water Retention and Nutrient Availability in a Highly-weathered Tropical Soil. PLoS ONE, 9, 1-9. http://dx.doi.org/10.1371/journal.pone.0098523

[16] Fellet, G., Marchiol, L., Delle Vedove, G. and Peressotti, A. (2011) Application of Biochar on Mine Tailings: Effects and Perspectives for Land Reclamation. Chemosphere, 83, 1262-1267. http://dx.doi.org/10.1016/j.chemosphere.2011.03.053

[17] Jones, B.E.H., Haynes, R.J. and Phillips, I.R. (2010) Effect of Amendment of Bauxite Processing Sand with Organic Materials on its Chemical, Physical and Microbial Properties. Journal of Environmental Management, 91, 2281-2288. http://dx.doi.org/10.1016/i.jenvman.2010.06.013

[18] Mukherjee, A. and Lal, R. (2013) Biochar Impacts on Soil Physical Properties and Greenhouse Gas Emissions. Agronomy Journal, 3, 313-339. http://dx.doi.org/10.3390/agronomy3020313

[19] Basso, A.S. (2012) Effect of Fast Pyrolysis Biochar on Physical and Chemical Properties of a Sandy Soil. Master's Thesis, Iowa State University, Ames.

[20] Piccolo, A., Pietramellara, G. and Mbagwu, J.S.C. (1997) Use of Humic Substances as Soil Conditioners to Increase Aggregate Stability. Geoderma, 75, 267-277.

[21] de Melo Carvalho, M.T., de Holanda Nunes Maia, A., Madari, B.E., Bastiaans, L., van Oort, P.A.J., Heinemann, A.B., Soler da Silva, M.A., Petter, F.A., Marimon Jr., B.H. and Meinke, H. (2014) Biochar Increases Plant-Available Water in a Sandy Loam Soil under an Aerobic Rice Crop System. Solid Earth, 5, 939-952. http://dx.doi.org/10.5194/se-5-939-2014

[22] Major, J., Rondon, M., Molina, D., Riha, S.J. and Lehmann, J. (2012) Nutrient Leaching in a Colombian Savanna Oxisol Amended with Biochar. Journal of Environmental Quality, 41, 1076-1086. http://dx.doi.org/10.2134/jeq2011.0128

[23] Sun, Z., Moldrup, P., Elsgaard, L., Arthur, E., Bruun, E.W., Hauggaard-Nielsen, H. and de Jonge, L.W. (2013) Direct and Indirect Short-Term Effects of Biochar on Physical Characteristics of an Arable Sandy Loam. Soil Science, 178, 465-473. http://dx.doi.org/10.1097/SS.0000000000000010

[24] United States Department of Agriculture, Natural Resources Conservation Service. Web Soil Survey. http://websoilsurvey.sc.egov.usda.gov/App/WebSoilSurvey.aspx

[25] Gee, G.W. and Bauder, J.W. (1986) Particle-Size Analysis. In: Klute, A., Ed., Methods of Soil Analysis, Part 1, Agronomy Monographs, ASA and SSSA, Madison, 383-411.

[26] Tucker, M.R. (1992) Determination of Phosphorus by Mehlich 3 Extractant. In: Donohue, S.J., Ed., Reference Soil and Media Diagnostic Procedure for the Southern Region of the United States, Southern Cooperative Series Bulletin 374, Virginia Agricultural Experiment Station, Blacksburg, 9-12.

[27] United States Environmental Protection Agency (1996) Method 3050B: Acid Digestion of Sediments, Sludges, and Soils. http://www.epa.gov/wastes/hazard/testmethods/sw846/pdfs/3050b.pdf

[28] Herath, H., Camps-Arbestain, M. and Hedley, M. (2013) Effect of Biochar on Soil Physical Properties in Two Contrasting Soils: An Alfisol and an Andisol. Geoderma, 209-210, 188-197. http://dx.doi.org/10.1016/j.geoderma.2013.06.016

[29] Bisdom, E.B.A., Dekker, L.W. and Schoute, J.F.T. (1993) Water Repellency of Sieve Fractions from Sandy Soils and Relationships with Organic Material and Soil Structure. Geoderma, 56, 105-118. http://dx.doi.org/10.1016/0016-7061(93)90103-R

[30] Dekker, L.W. and Jungerius, P.D. (1990) Water Repellency in the Dunes with Special Reference to the Netherlands. 
Catena Supplement, 18, 173-183.

[31] Brye, K.R. (2003) Long-Term Effects of Cultivation on Particle Size and Water-Retention Characteristics Determined Using Wetting Curves. Soil Science, 168, 459-468. http://dx.doi.org/10.1097/01.ss.0000080331.10341.36

[32] Downie, A., Crosky, A. and Munroe, P. (2009) Physical Properties of Biochar. In: Lehmann, J. and Joseph, S., Eds., Biochar for Environmental Management: Science and Technology, Earthscan, London, 13-32.

[33] Ouyang, L., Wang, F., Tang, J., Yu, L. and Zhang, R. (2013) Effects of Biochar Amendment on Soil Aggregates and Hydraulic Properties. Journal of Soil Science and Plant Nutrition, 13, 991-1002.

[34] Lehmann, J., Czimezik, C., Laird, D. and Sohi, S. (2009) Stability of Biochar in the Soil. In: Lehmann, J. and Joseph, S., Eds., Biochar for Environmental Management: Science and Technology, Earthscan, London, 184-205.

[35] Briggs, C., Breiner, J.M. and Graham, R.C. (2012) Physical and Chemical Properties of Pinus ponderosa Charcoal: Implications for Soil Modification. Soil Science, 177, 263-268. http://dx.doi.org/10.1097/SS.0b013e3182482784

[36] Amonette, J.E. and Joseph, S. (2009) Characteristics of Biochar: Microchemical Properties. In: Lehmann, J. and Joseph, S., Eds., Biochar for Environmental Management: Science and Technology, Earthscan, London, 33-52.

[37] Antal, M.J. and Grønli, M. (2003) The Art, Science, and Technology of Charcoal Production. Industrial and Engineering Chemistry Research, 42, 1619-1640. http://dx.doi.org/10.1021/ie0207919

[38] Kameyama, K., Miyamoto, T. and Shinogi, Y. (2010) Increase in Available Water Content of Soils by Applying Bagasse-Charcoals. Proceedings of the 19th World Congress of Soil Science, Soil Solutions for Changing World, Brisbane, 1-6 August 2010, P-0155.

[39] Hardie, M., Clothier, B., Bound, S., Oliver, G. and Close, D. (2014) Does Biochar Influence Soil Physical Properties and Soil Water Availability? Plant and Soil, 376, 347-361. http://dx.doi.org/10.1007/s11104-013-1980-x

[40] Tryon, E.H. (1948) Effect of Charcoal on Certain Physical, Chemical, and Biological Properties of Forest Soils. Ecological Monographs, 18, 81-115. http://dx.doi.org/10.2307/1948629

[41] Streubel, J.D., Collins, H.P., Garcia-Perez, M., Tarara, J., Granatstein, D. and Kruger, C.E. (2011) Influence of Contrasting Biochar Types on Five Soils at Increasing Rates of Application. Soil Science Society of America Journal, 75, 1402-1413. http://dx.doi.org/10.2136/sssaj2010.0325

[42] Abel, S., Peters, A., Trinks, S., Schonsky, H., Facklam, M. and Wessolek, G. (2013) Impact of Biochar and Hydrochar Addition on Water Retention and Water Repellency of Sandy Soil. Geoderma, 202-203, 183-191. 
Scientific Research Publishing (SCIRP) is one of the largest Open Access journal publishers. It is currently publishing more than 200 open access, online, peer-reviewed journals covering a wide range of academic disciplines. SCIRP serves the worldwide academic communities and contributes to the progress and application of science with its publication.

Other selected journals from SCIRP are listed as below. Submit your manuscript to us via either submit@scirp.org or Online Submission Portal.
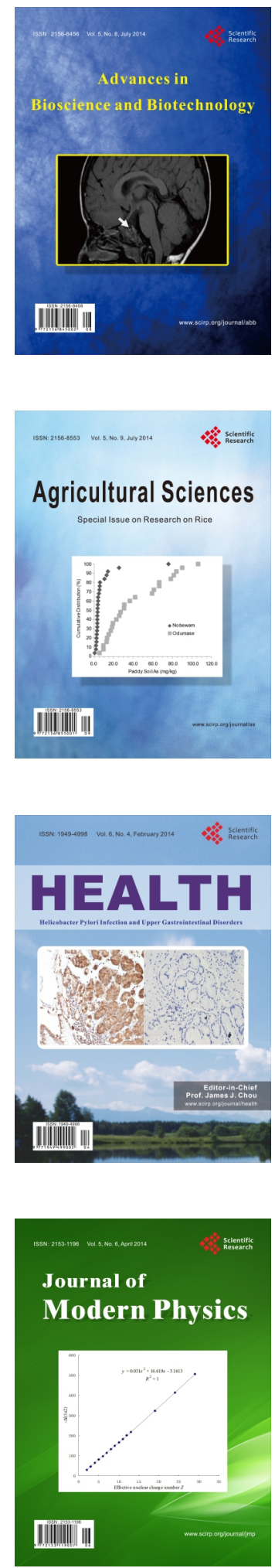
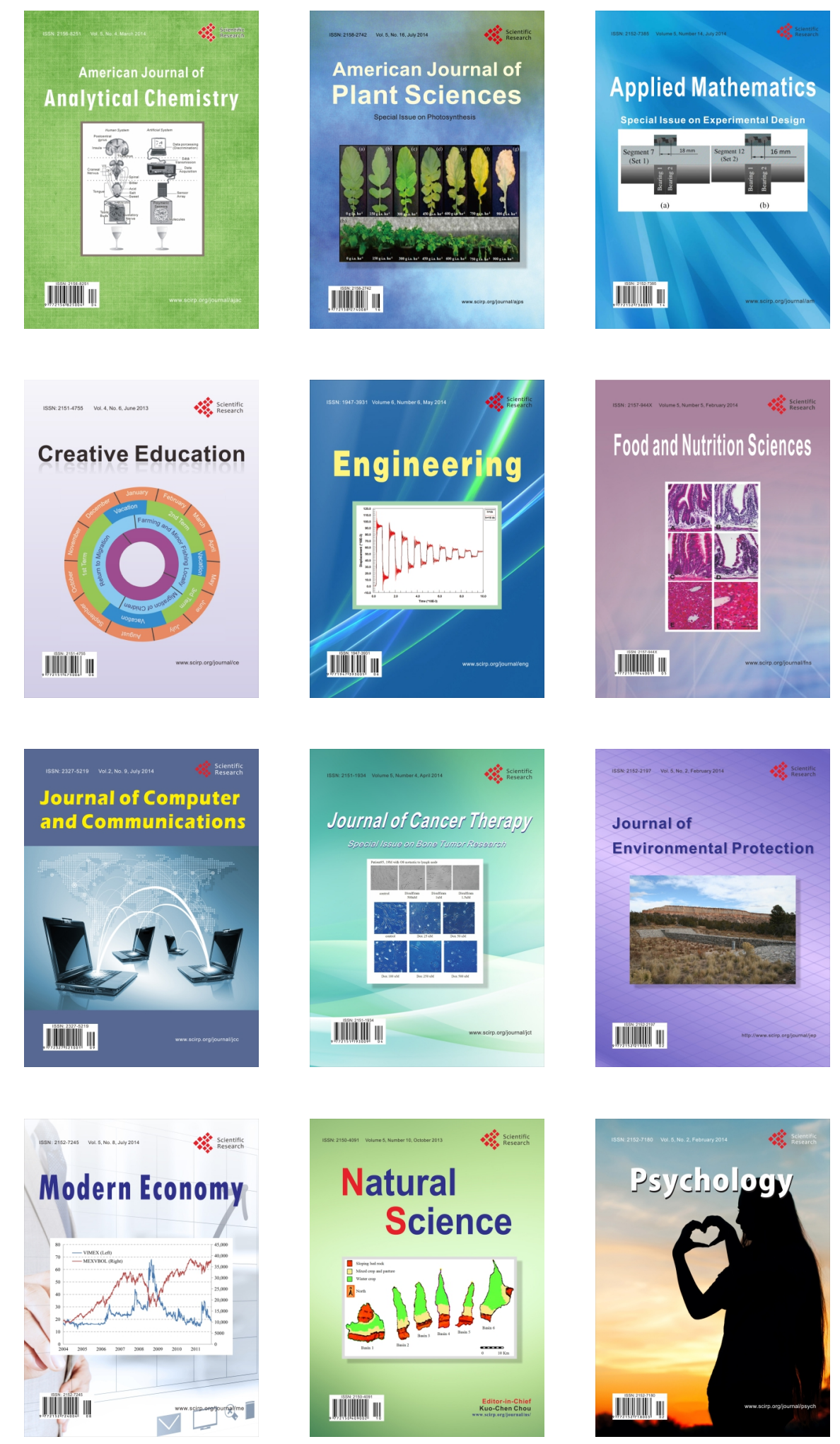